\title{
Radiofrequency Electromagnetic Field Affects Heart Rate Variability in Rabbits
}

\author{
Jakub MISEK ${ }^{1}$, Marcel VETERNIK ${ }^{1}$, Ingrid TONHAJZEROVA ${ }^{2}$, Viera JAKUSOVA ${ }^{3}$, \\ Ladislav JANOUSEK ${ }^{4}$, Jan JAKUS ${ }^{1}$
}

${ }^{1}$ Comenius University in Bratislava, Jessenius Faculty of Medicine in Martin, Department of Medical Biophysics, Martin, Slovakia, ${ }^{2}$ Comenius University in Bratislava, Jessenius Faculty of Medicine in Martin, Department of Physiology JFM CU, 1 Biomedical Center Martin JFM CU, Martin, Slovakia, ${ }^{3}$ Comenius University in Bratislava, Jessenius Faculty of Medicine in Martin, Department of Public Health, Martin, Slovakia, ${ }^{4}$ University of Zilina, Faculty of Electrical Engineering and Information Technology, Department of Electromagnetic and Biomedical Engineering, Zilina, Slovakia

Received December 20, 2019

Accepted April 22, 2020

Epub Ahead of Print July 16, 2020

\section{Summary}

The aim of this study was to assess the effects of radiofrequency electromagnetic field (RF EMF) on heart rate variability (HRV) in rabbits with intensity slightly exceeding the limits for occupations. Totally $21 \mathrm{New}$ Zealand white rabbits divided into two groups were used in this double-blind study. The first group of animals without general anesthesia was subjected to HRV examination under exposure to a device generated RF EMF source (frequency $1788 \mathrm{MHz}$, intensity $160 \mathrm{~V} / \mathrm{m}$, lasting $150 \mathrm{~min}$.). The second group (premedications $+\mathrm{a}$ chloralose $\mathrm{mg} / \mathrm{kg}$ ) underwent the same protocol under the exposure to the real RF EMF signal from the base stations of mobile providers (frequency range 1805 $1870 \mathrm{MHz}$ - corresponding to the downlink signal of Slovak mobile providers, $160 \mathrm{~V} / \mathrm{m}, 150 \mathrm{~min}$., respectively). Individual 5-min records were used to analyze the HRV parameters: heart rate and root Mean Square of the Successive Differences (rMSSD) for time domain analysis and spectral powers in the low (LF-VFS) and high frequency (HF-VFS) bands for frequency domain analysis. Our study revealed the increased in HRV parameters (HF-HRV, rMSSD) associated with lower heart rate indicating increased cardiac vagal control under the exposure to RF EMF in experimental methods.

\section{Key words}

Cardiac autonomic regulation - Cell phone - Radiofrequency electromagnetic exposure $\bullet$ Mobile communication $\bullet$ Rabbits

\section{Corresponding author}

Jan Jakus, Comenius University in Bratislava, Jessenius Faculty of Medicine in Martin, Department of Medical Biophysics, Mala Hora 4, 03601 Martin, Slovakia. E-mail: jakus1@uniba.sk, jakus330@gmail.com

\section{Introduction}

The wireless cell phone technology is based on the broadcasting of radiofrequency (RF) signal using the antennas usually attached to the base transceiver stations (BTSs). The number of BTSs increases with an extensive usage of the cell phones and mobile telecommunication techniques. Higher number of BTSs in the rural environment may result in potential hazard for living beings regarding the exposure to radiofrequency electromagnetic fields (RF EMF).

Heart rate variability (HRV) is characterized as the oscillations of heart rate around its mean value mediated predominantly by cardiac autonomic regulation (Bujnakova et al. 2016, Veternik et al. 2018). Thus, analysis of HRV may indicate changes in dynamic sympathetic-vagal balance indicating flexibility and adaptability of the organism (Camm et al. 1996). It has been shown that different parameters of EMF may have certain detrimental effects on the cell (e.g. Raček et al. 
2018, Průcha et al. 2019) and cardiovascular system (e.g. Belyaev et al. 2016, Durdik et al. 2019). However, there is still not enough evidence on RF EMF exposure and its possible negative health effects. Our previous study (Misek et al. 2018a) revealed increase in vagal activity after the exposure to generated RF EMF in humans with intensity close to the safety limits for general public (58 V/m for GSM1800). Gmitrov (2007) reported that static magnetic field can modulate the arterial baroreflex control. Other studies described increase in heart rate (HR) under exposure to WiFi routers (Saili et al. 2015) and an appearance of arrhythmia in railroad workers after the exposure to intensities $26 \mathrm{kV} / \mathrm{m}$ (Creasey and Goldberg, 1993). Long-term exposure to radiation of BTSs and TV stations can also lead to higher chance of arterial hypertension (Vangelova et al. 2006). As reported by $\mathrm{Yu}$ and Peng (2017) higher incidence of abnormal electrocardiograms (ECGs) was seen in radio technicians, working in their jobs for an average of 14 years. They have also informed that male boat crews who worked in the EMF environment for an average of 4.4 years, had a significantly lower HR comparing to the control proposing the possible effect of an EMF. In addition, computer simulations proved that implantable devices may reach or even exceed the safety limit values (Psenakova et al. 2016, Smondrk et al. 2018). Contrary, there also were published studies reported no effects of RF EMF on HRV (e.g. Parazzini et al. 2013).

Almost all studies have used limit values of EMF given by the International Commission on Non-Ionizing Radiation Protection (ICNIRP 1998) for general public. However, for example the workers performing maintenance tasks in a close vicinity to the transmitting equipment were exposed to higher $\mathrm{RF}$ exposure values compare to those valid for general public (Alanko et al. 2008). Thus, the aim was to study the effects of RF EMF on cardiac autonomic control indexed by HRV short-term analysis under two distinct exposure conditions in experimental models.

\section{Materials and Methods}

\section{Study group and exposure protocol}

Totally 21 New Zealand white rabbits of both genders (divided into two groups) were used in this double-blind study.

The group 1 embraced 10 animals $(3.7 \pm 0.5 \mathrm{~kg})$ examined under exposure to a generated RF EMF source without anesthetics, sedatives or other medications.
A somnolent state occurred by slow stroking and a talk with a monotonic voice, what allowed simple non-invasive procedures to be performed. Under this condition, the chest fur of rabbit was cut, the electroconductive gel was applied and ECG rubber band with electrodes was placed. Subjects were examined in a quiet room with the same light intensity under standard conditions (temperature: $18-20^{\circ} \mathrm{C}$, relative humidity: 50 $-55 \%$ ). Each animal in the group 1 was kept at rest for $30 \mathrm{~min}$. to stabilize the HRV parameters before the experiment. The exposure setup used for the group 1 was described in details at our previous study (Misek et al. 2018a). The loop antenna (Galuscak and Hazdra 2008) was tuned to $1788.0 \mathrm{MHz}$. Pulse modulated sine wave with pulse width of $100 \mu \mathrm{s}$ was generated by the signal generator Agilent N9310A (Agilent Technologies, USA) and amplified with the $5 \mathrm{~W}$ amplifier 5S1G4 (Amplifier Research, USA) set to output power $2 \mathrm{~W}$.

The group 2 embraced 11 animals $(4.2 \pm 0.2 \mathrm{~kg})$. They were exposed to the same experimental protocol as animals in the group 1, however, the exposure signal employed the real Global System for Mobile Communications (GSM) signal produced by the base stations (BTS). The Faraday cage in which the rabbits were held during the exposure does not allow the free movement of the animals. Thus, the animals in the group 2 underwent the examination in general anesthesia. Surgical procedures were started with premedication Zoletil 100 (Virbac, France) at a dose $30 \mathrm{mg} / \mathrm{kg}$ i.m. Zoletil has no cumulative effect, with little effect on metabolism, and can selectively disrupt the sensory inputs to the brain. Thus, rabbits may have their eyes open, swallow, move their tongue, blink, and even slightly move their limbs. The depth of anesthesia during surgical procedures was monitored by the escape reflex (where the painful stimulation or stretching of the limb led to its flexion), also by the palpebral (blinking) reflex and the corneal reflex. The premedication had a faster onset (in minutes) and took time about 20-30 $\mathrm{min}$. Subsequently, $\alpha$-chloralose (Sigma-Aldrich, USA) at a dose of $60 \mathrm{mg} / \mathrm{kg}$ i.p. was administered. This anesthesia had a slow onset (approximately $60 \mathrm{~min}$ ) but a longlasting effect (several hours). Chloralose does not significantly affect autonomic nervous system (ANS) activity compared to other types of anesthetics and sedatives, hence allowing us to analyze HRV. The $25 \mathrm{~mm}$ long needle electrodes were placed under a skin along the sternum on the left and right sides in order to record heart signal important for HRV analysis. Since HRV is 
influenced by afferent stimuli, only a few basic surgical interventions were performed: the venous catheter was introduced into femoral vein for fluid and drug administration, and a tracheostomy with inserted canula enabled monitoring of number of breaths and end-tidal $\mathrm{CO}_{2}$. The animals were breathed spontaneously, as well. In some occasions animals were allowed to breath mixture of $100 \%$ medical oxygen with air. The local anesthetic Mesocain s.c. was applied in all surgical procedures as necessary. Body temperature was held at $38-40{ }^{\circ} \mathrm{C}$ using an IR lamp that does not emit RF EMF. Animals in the group 2 relaxed for 120-180 min. in order to reach an appropriate depth of the anesthesia before the experiment. Each rabbit from the group 2 was placed in the prone position to the Faraday cage without touching or other disturbing during the HRV measurements. They were exposed by the real telecommunication signal obtained from BTSs in the frequency range 1805 - 1870 $\mathrm{MHz}$ that corresponds to downlink signal of Slovak mobile providers. The exposure system was described in details elsewhere (Misek et al. 2018b). Shortly, an antenna placed on the roof of the building collected up the signal emitted by BTSs. The signal was then filtered, amplified (ELPRA-technik, Slovakia) and exposed to the Faraday cage in the laboratory. Only one animal was placed in the cage a time preventing mutual couplings between the biological objects. Placing more than one object to the cage could result to unequal absorption for each animal (Trzaska 2015).

In both groups, the intensity of the electric field (E) was set to $160 \mathrm{~V} / \mathrm{m}$ measured by the Narda $550 \mathrm{NBM}$ broadband meter (Narda Safety Test Solutions, Germany). It corresponds to approximately $25 \%$ higher limit value According to Directive 2013/35 / EU of the European Parliament and Council, where the limit value is set to $127 \mathrm{~V} / \mathrm{m}$ for a given frequency band. The loop antenna was suspended $5 \mathrm{~cm}$ from the head of the rabbits in the reactive part of the near field. In particular, an occipital lobe and the cerebellum regions of the rabbits were exposed totally for $150 \mathrm{~min}$.

Previous studies have shown that extremely low frequency (ELF) magnetic background field, may interfere with the effects of RF EMF (Barabas and Radil 2012, Barabas et al. 2015, Belyaev 2010, Koppel et al. 2018). Thus, background ELF magnetic flux density did not exceed $90 \mathrm{nT}$ for the frequency band of $5-100 \mathrm{~Hz}$, $67 \mathrm{nT}$ for $100 \mathrm{~Hz}-10 \mathrm{kHz}$, and $52 \mathrm{nT}$ for $10-100 \mathrm{kHz}$ as measured with Narda EHP50-D (Narda Safety Test Solution, Germany) at the location of exposure.

At the end of the experiment, animals in both groups were sacrificed by an overdose of sodium pentobarbital (Morbital, Biowet, Poland, $160 \mathrm{mg} / \mathrm{kg}$ i.v.) and by final injection of $5 \mathrm{ml}$ of Potassium chloride (KCl) i.v.

\section{Protocol of experimental procedure}

HRV was monitored continuously throughout the whole experiment. Rabbits in the both groups were subjected to HRV measurement with the same protocol divided into 7 periods (Fig. 1). Control HRV measurements (sham exposure) were recorded during Period I. $30 \mathrm{~min}$. before the experiment and during Period VII. $30 \mathrm{~min}$. after the experiment. All devices in the lab were switched to standby mode with the EMF turned off. During Periods II. - VI. the cranial part of the animal was exposed by RF EMF, focusing on the parietal-occipital region of the head and the associated parts of the neck. An ECG signal was recorded every $30 \mathrm{~min}$. after each trial period.

RF EMF exposure

Period I. Period II. Period III. Period IV. Period V. Period VI. Period VII.

\begin{tabular}{|l|l|l|l|l|l|l|}
\hline Control & $30 \mathrm{~min}$ & $60 \mathrm{~min}$ & $90 \mathrm{~min}$ & $120 \mathrm{~min}$ & $150 \mathrm{~min}$ & Control \\
\hline
\end{tabular}

\section{HRV measurement}

Fig. 1. Experimental protocol proposing 7 periods. Period I. and II. served for control measurements before and after the experiment. All animals in both groups underwent the same exposure protocol. During periods II. - VI. either the generated (Group I., $n=10)$ or real telecommunication (Group II., $\mathrm{n}=11$ ) RF EMF signal was applied. 
Heart rate variability analysis

ECG signal using one-lead was continuously recorded during all experiment (Periods I. - VII.) using HRV system adjusted for experimental models DiANS PF8 with VarCor PF7 preamplifier (Dimea Group, Czech Republic). The artefacts were manually removed from ECG recordings according to the generally accepted recommendations (Camm et al. 1996, Shaffer and Ginsberg 2017).

Consequently, the five-minute intervals were used for time domain and spectral HRV analysis. Specifically, the following parameters of HRV time analysis were evaluated: RR interval [ms] providing information about mean heart rate, rMSSD (root Mean Square of the Successive Differences) [s] indicating cardiovagal regulation and respiration rate. Spectral (frequency) analysis of cardiac time series was used to determine two distinct bands according to Mokrý et al. (2006): the spectral power in low frequency (LF-HRV: $0.04-0.15$ $\mathrm{Hz})\left[\mathrm{ms}^{2}\right]$ and spectral power in the high frequency (HFHRV: $0.15-2.0 \mathrm{~Hz})\left[\mathrm{ms}^{2}\right]$ bands. Parasympathetic activity contributes mainly to the HF-HRV component whereas the LF-HRV component mostly reflects the sympathetic and baroreceptor's modulation. In addition, total spectral power
(TSP-HRV) $\left[\mathrm{ms}^{2}\right]$ was evaluated as an index of total HRV.

\section{Temperature measurements}

The body temperature of animals was measured between each of the Periods I. - VII. The measurement accuracy was $0.1{ }^{\circ} \mathrm{C}$ in both groups. To measure the temperature in the group 1 the thermovision camera Flir i3 (FLIR systems, USA) was used. Readings were made always from the same place at boundary of the external auditory canal and pinna. At this point, the skin contains the smallest amount of fur that could block heat transfer. Each thermographic image was post-processed by the Flir Tools software v. 3.1. (FLIR systems, USA), which allows selection of the desired region of interest for temperature analysis. The software then automatically calculated the average temperature value in the indicated area to eliminate the measurement error.

The temperature probe BAT-12 (Physitemp Instruments, USA) was introduced subcutaneously at the forehead of the animals in the group 2. Since the metallic parts of the probe (type $\mathrm{T}$ thermocouple) directly interact with EMF, the temperature readings were performed during short-term deactivation of the EMF between each exposure Period II. - VI.

Table 1. HRV analysis in rabbits exposed to device generated RF EMF signal.

\begin{tabular}{|c|c|c|c|c|c|c|c|c|}
\hline Group 1 & & I. & $\begin{array}{c}\text { II. } \\
\text { 30min }\end{array}$ & $\begin{array}{l}\text { III. } \\
\text { 60min }\end{array}$ & $\begin{array}{c}\text { IV. } \\
\text { 90min }\end{array}$ & $\begin{array}{c}V . \\
120 \mathrm{~min}\end{array}$ & $\begin{array}{c}\text { VI. } \\
\text { 150min }\end{array}$ & VII. \\
\hline$L F-H R V$ & $\mathrm{p}$ & & ns & ns & ns & ns & ns & ns \\
\hline \multirow[t]{2}{*}[ms^{2}]{} & $\bar{x}$ & 18.1 & 18.8 & 21.2 & 20.1 & 19.5 & 21.0 & 28.1 \\
\hline & SD & 10.1 & 8.4 & 11.5 & 9.9 & 8.0 & 3.9 & 15.0 \\
\hline \multirow{3}{*}{$\begin{array}{l}H F-H R V \\
{\left[m s^{2}\right]}\end{array}$} & $\mathrm{p}$ & & $\mathrm{ns}$ & ns & $\mathrm{ns}$ & $*$ & $\mathrm{~ns}$ & $\mathrm{~ns}$ \\
\hline & $\bar{x}$ & 17.5 & 20.3 & 22.1 & 27.1 & 30.5 & 44.3 & 45.1 \\
\hline & SD & 9.8 & 11.3 & 12.6 & 14.0 & 14.9 & 32.5 & 40.3 \\
\hline \multirow{3}{*}{$\begin{array}{l}T S P-H R V \\
{\left[m s^{2}\right]}\end{array}$} & $\mathrm{p}$ & & ns & ns & $\mathrm{ns}$ & ns & ns & $*$ \\
\hline & $\bar{x}$ & 35.5 & 39.1 & 43.3 & 47.2 & 50.1 & 65.2 & 73.1 \\
\hline & SD & 18.7 & 17.3 & 20.1 & 19.5 & 20.7 & 35.2 & 45.7 \\
\hline \multirow{3}{*}{$R R[m s]$} & $\mathrm{p}$ & & ns & ns & ns & ns & ns & ns \\
\hline & $\bar{x}$ & 310.0 & 315.6 & 313.8 & 317.2 & 324.2 & 328.3 & 325.6 \\
\hline & SD & 30.9 & 41.7 & 38.6 & 33.3 & 31.7 & 39.6 & 27.1 \\
\hline \multirow{3}{*}{$\begin{array}{l}r M S S D \\
{[s]}\end{array}$} & $\mathrm{p}$ & & $\mathrm{ns}$ & ns & $\mathrm{ns}$ & $\mathrm{ns}$ & $*$ & ns \\
\hline & $\bar{x}$ & 5.1 & 5.7 & 6.2 & 7.3 & 7.5 & 9.6 & 8.9 \\
\hline & SD & 1.9 & 2.5 & 2.5 & 2.9 & 3.0 & 4.5 & 4.4 \\
\hline \multirow{3}{*}{$\begin{array}{l}\text { Respiration } \\
\text { rate }\end{array}$} & $\mathrm{p}$ & & ns & ns & ns & ns & ns & ns \\
\hline & $\bar{x}$ & 20.2 & 19.7 & 20.3 & 20.6 & 20.1 & 20.6 & 21.0 \\
\hline & SD & 1.0 & 0.7 & 1.5 & 1.8 & 1.3 & 0.8 & 1.5 \\
\hline
\end{tabular}

$\bar{x}$ - mean value, SD - Standard deviation, $\mathrm{ns}-$ not significant, $* \mathrm{p}<0.05$ (significance calculated comparing to Period I.) For explanation of individual parameters, see Results. 
Statistics

Statistical analysis was provided using MS Office Excel and GraphPad InStat (La Jolla, USA) software. The Gaussian/non-Gaussian distribution was assessed by the Kolmogorov-Smirnov test. Consequently, Student's paired t-test was applied for RR, rMSSD and respiration rate and Wilcoxonov t-test for LF-HRV, HF-HRV and TSP-HRV to determine the $p$ values followed by the adjustment of multiple comparisons using the False Discovery Rate (FDR) method. The $\mathrm{p}<0.05$ was considered as significant.

\section{Results}

HRV analysis

In the group 1, the duration of RR intervals does not reveal any statistically significant changes (Table 1). The HRV parameters significantly changed: rMSSD significantly raised in the Period VI., HF-HRV in the Period V. and TSP-HRV in the Period VII. (compared to the Period I., $\mathrm{p}<0.05$ ).

In the group 2, statistically significant prolongation of the RR was observed in the Periods II.,
III. (compared to the Period I., $\mathrm{p}<0.01$ ) and Periods IV. - VII. (compared to the Period I., p<0.05) (Table 2). The HRV parameters significantly changed: rMSSD increased in all Periods II. - VII. (compared to the Period I., $\mathrm{p}<0.05$ ). Also HF-HRV significantly raised in Period VI., LF-HRV in Period VII. and TSP-HRV in Periods IV. - VII. (compared to the Period I., $\mathrm{p}<0.05$ ).

\section{Temperature changes:}

In the group 1 we observed the elevation of the temperature in Period III. compared to the Period I. $(\mathrm{p}<0.05)$ (Table 3$)$.

\section{Discussion}

The main results revealed that the animals in the groups 1 and 2 were characterized by increase in vagal activity during the exposure to RF EMF comparing to the pre-exposure conditions. Other findings showed 1.) significant prolongation in RR intervals indicating lower HR in both groups, 2.) increase in rMSSD (Group 1: Period VI., Group 2: Periods II. - VII.), HF-HRV (Group 1: Period V., Group 2: Period VI.) and TSP-HRV

Table 2. HRV analysis in rabbits exposed to real RF EMF signal.

\begin{tabular}{|c|c|c|c|c|c|c|c|c|}
\hline Group 2 & & I. & $\begin{array}{c}\text { II. } \\
\text { 30min }\end{array}$ & $\begin{array}{l}\text { III. } \\
\text { 60min }\end{array}$ & $\begin{array}{c}\text { IV. } \\
\text { 90min }\end{array}$ & $\begin{array}{c}V . \\
120 \mathrm{~min}\end{array}$ & $\begin{array}{c}\text { VI. } \\
\text { 150min }\end{array}$ & VII. \\
\hline \multirow{3}{*}{$\begin{array}{l}L F-H R V \\
{\left[m s^{2}\right]}\end{array}$} & $\mathrm{p}$ & & ns & ns & $\mathrm{ns}$ & $\mathrm{ns}$ & $\mathrm{ns}$ & $*$ \\
\hline & $\bar{x}$ & 2.1 & 3.4 & 4.5 & 5.4 & 6.6 & 9.1 & 10.0 \\
\hline & $\mathrm{SD}$ & 2.5 & 3.7 & 4.1 & 5.1 & 7.7 & 10.0 & 7.3 \\
\hline \multirow{3}{*}{$\begin{array}{l}H F-H R V \\
{\left[m s^{2}\right]}\end{array}$} & $\mathrm{p}$ & & $\mathrm{ns}$ & $\mathrm{ns}$ & ns & $\mathrm{ns}$ & $*$ & $\mathrm{~ns}$ \\
\hline & $\bar{x}$ & 2.6 & 3.7 & 3.6 & 4.5 & 5.6 & 6.7 & 6.1 \\
\hline & SD & 1.8 & 3.0 & 2.8 & 3.8 & 3.6 & 4.2 & 5.0 \\
\hline \multirow{3}{*}{$\begin{array}{l}T S P-H R V \\
{\left[m s^{2}\right]}\end{array}$} & $\mathrm{p}$ & & $\mathrm{ns}$ & ns & $*$ & $*$ & $*$ & $*$ \\
\hline & $\bar{x}$ & 4.8 & 7.1 & 8.1 & 9.9 & 12.3 & 15.7 & 16.1 \\
\hline & SD & 4.0 & 5.9 & 6.8 & 8.2 & 10.8 & 13.0 & 10.1 \\
\hline \multirow{3}{*}{$R R[m s]$} & $\mathrm{p}$ & & $* *$ & $* *$ & $*$ & $*$ & $*$ & $*$ \\
\hline & $\bar{x}$ & 262.7 & 274.5 & 277.4 & 283.0 & 284.4 & 288.5 & 286.9 \\
\hline & $\mathrm{SD}$ & 26.1 & 29.9 & 32.6 & 35.7 & 35.4 & 38.3 & 34.0 \\
\hline \multirow{3}{*}{$\begin{array}{l}r M S S D \\
{[s]}\end{array}$} & $\mathrm{p}$ & & $* *$ & $* *$ & $* *$ & $* *$ & $* *$ & $* *$ \\
\hline & $\bar{x}$ & 1.5 & 2.0 & 2.2 & 2.4 & 2.9 & 3.1 & 3.0 \\
\hline & $\mathrm{SD}$ & 0.2 & 0.4 & 0.5 & 0.6 & 0.8 & 0.5 & 0.9 \\
\hline \multirow{3}{*}{$\begin{array}{l}\text { Respiration } \\
\text { rate }\end{array}$} & $\mathrm{p}$ & & ns & ns & $\mathrm{ns}$ & ns & ns & ns \\
\hline & $\bar{x}$ & 19.9 & 20.0 & 19.9 & 20.2 & 20.3 & 20.0 & 20.2 \\
\hline & $\mathrm{SD}$ & 1.7 & 1.5 & 1.7 & 1.2 & 1.4 & 1.0 & 1.3 \\
\hline
\end{tabular}

$\bar{x}-$ mean value, SD - Standard deviation, ns - not significant, $* \mathrm{p}<0.05, * * \mathrm{p}<0.01$ (significance calculated comparing to Period I.) Other parameters are the same as seen in Table 1 
Table 3. Temperature analysis in rabbits during the exposure to RF EMF

\begin{tabular}{|c|c|c|c|c|c|c|c|}
\hline Group 1 & I. & $\begin{array}{c}\text { II. } \\
\text { 30 min }\end{array}$ & $\begin{array}{l}\text { III. } \\
\text { 60min }\end{array}$ & $\begin{array}{c}\text { IV. } \\
\text { 90min }\end{array}$ & $\begin{array}{c}V . \\
120 \mathrm{~min}\end{array}$ & $\begin{array}{c}\text { VI. } \\
\text { 150min }\end{array}$ & VII. \\
\hline$p$ & & $\mathrm{~ns}$ & $*$ & $\mathrm{~ns}$ & $\mathrm{~ns}$ & $\mathrm{~ns}$ & $\mathrm{~ns}$ \\
\hline $\bar{x}$ & 38.36 & 38.57 & 38.83 & 38.77 & 38.77 & 38.76 & 38.59 \\
\hline$S D$ & 1.02 & 1.14 & 0.91 & 0.87 & 0.93 & 1.08 & 0.94 \\
\hline$\Delta T$ & & 0.21 & 0.47 & 0.41 & 0.41 & 0.40 & 0.23 \\
\hline \multicolumn{8}{|l|}{ Group 2} \\
\hline$p$ & & ns & $\mathrm{ns}$ & ns & $\mathrm{ns}$ & ns & $\mathrm{ns}$ \\
\hline $\bar{x}$ & 40.78 & 40.93 & 40.95 & 40.94 & 40.95 & 40.94 & 40.89 \\
\hline$S D$ & 0.08 & 0.08 & 0.05 & 0.06 & 0.15 & 0.12 & 0.11 \\
\hline$\Delta T$ & & 0.15 & 0.17 & 0.16 & 0.17 & 0.16 & 0.11 \\
\hline
\end{tabular}

$\bar{x}$ - mean value, SD - Standard deviation, $\Delta \mathrm{T}$ - temperature difference compared to Period I. ns - not significant, $* \mathrm{p}<0.05$ (significance calculated comparing to Period I.)

(Group 1: Period VII., Group 2: Periods IV. - VII.) indicating increase in vagal activity. However, we suggest that steep rise in TSP-HRV (mainly in the group 2) could be related to animal species, and as an effect of the anesthesia. 3.) temperature increased during Period III. only in the group 1. Several mechanisms are supposed.

Firstly, the supine position represents a physiological mechanism in which cardiac-linked parasympathetic efferents are maximized resulting in lower HR and higher HRV. In this respect, HRV is primary mediated by a modulation of parasympathetic nerve activity, which represents a physiological adaptive response to the recumbence by controlling HR. In our study, the bradycardic reaction ended $30 \mathrm{~min}$ after the EMF exposure, indicating modulation by direct or indirect effect of RF EMFs on chronotropic regulation of the heart. In a line with our previous findings on humans, this condition was observed as shifting cardiac autonomous dynamic equilibrium towards to the parasympathetic nerve activity indexed by a significant increase in total HRV, and particularly with an increase in HF-HRV and rMSSD parameters (Misek et al. 2018a).

Our results were in accordance to other studies which revealed the effects of magnetic fields on the cardiovascular system (Lazetic and Nikin 1988). A significant decrease in HR was observed during the exposure (21.3 $\mathrm{mT}, 150 \mathrm{~min})$, compared to the controls. The bradycardic effect was reported by Jeong et al. (2005) revealing that 1-day exposure to EMF $(60 \mathrm{~Hz}$,
$20 \mathrm{G}$ ) could suppress dobutamine-induced tachycardia by affecting ventricular repolarization in rats. Saili et al. (2015) exposed adult rabbits to WiFi (2.45 GHz) for 1 hour resulting in a rise in $\mathrm{HR}$ and blood pressure. In addition, the authors reported cardiac arrhythmias and changes in catecholamine levels (dopamine, epinephrine), suggesting that the RF EMF may directly or indirectly affect the cardiovascular system through the ligand-gated receptors. Mohamed et al. (2011) exposed rats to RF EMF from a cell phone using $1800 \mathrm{MHz}$ frequency band for 4 and 8 weeks. They referred increase in the sympathetic nerve activity based on tachycardic reaction and hypertension during $4^{\text {th }}$ week of the experiment. However, the authors also observed bradycardia effect after 8 weeks of the exposure with histopathological changes in the myocardium accompanied by hypocalcaemia. The authors reported that observed hypocalcemia, might be one of the mechanisms by which EMF interacts with biological tissues. Kopani et al. (2017) revealed the formation of iron deposits in the cerebellum after RF EMF exposure $(1800 \mathrm{MHz}$ band, $160 \mathrm{~V} / \mathrm{m}, 150 \mathrm{~min}$ ) in the rabbits. The authors also found changes in thickness of a cell membrane and dystrophic changes on neurons in the region of the stratum molecule, stratum gangliosum of cerebellum and Purkinje cells compared to the control, confirming that multiple CNS regions were affected by EMF. Purkinje cells serve as a GABAergic (gamma-aminobutyric acid) system. GABA is neurotransmitter acts on inhibitory synapses of pre- and post-synaptic neurons regulating the excitability 
of neurons in the brain. Purkinje cells are electrophysiologically capable of spontaneously switching their activity from resting to excited and vice versa (Loewenstein et al. 2005). Modeling of this situation has shown that intracellular calcium may be responsible for such switching (Forrest 2014) what was later proven on awake animals (Yartsev et al. 2009). Several studies have shown that intracellular calcium (particularly hypocalcaemia) or changes in the cell ion channels affected by EMFs what may changes electrical activity on the membranes leading to alternations of neuronal activity (e.g. Ghazizadeh and Naziroglu 2014, Kim et al. 2019a, Kim et al. 2019b, Maskey et al. 2010, Pall 2015). Khadrawy et al. (2009) and Noor et al. (2011) exposed adult and young rats with a $217 \mathrm{~Hz}$ modulated $900 \mathrm{MHz}$ (SAR $1.165 \mathrm{~W} / \mathrm{kg}, 0.2 \mathrm{~W} / \mathrm{m}^{2}$ ) to detect changes in neurotransmitters in the cerebral cortex for $1 \mathrm{~h}, 1,2$, and 4 months. After one hour of exposure, significant changes in the concentration of excitatory (increase in glutamate, increase in aspartate, decrease in glutamine) and inhibitory transmitters (increase in GABA, increase in glycine) were observed in both studies compared to control. The authors report that an increase in cortical GABA levels may be a mechanism by which the brain alleviates a state of hyperexcitability by a compensatory mechanism. Thus, the recorded changes in the levels of amino acids may potentially be an explanation of the changes in cortical excitability after the exposure to RF EMF leading to a change in the chronotropic heart regulation (HRV). In this aspect, the central autonomic network (CAN) represents network of brainstem and forebrain regions that are implicated in both baseline ANS function, as well as the modulation of ANS function in response to changing environments. Importantly, the CAN is under tonic inhibitory control achieved by GABA interneurons within the nucleus tractus solitarii. Moreover, the vagal outputs of the CAN coming into sinoatrial node produces the complex beat-to-beat HR oscillations - HRV, therefore, the HRV analysis could represent a noninvasive window into neurocardiac regulatory integrity (Benarroch 1993, Sklerov et al. 2019, Thayer and Lane 2000). We suggest that RF-EMF linked abnormalities in complex neurocardiac integrity could result in altered cardiac vagal control as a risk factor for cardiovascular morbidity.

With respect to temperature, our results showed a sudden increase in the temperature at $60 \mathrm{~min}$. (Period III.) of the exposure only in group 1. It is attributed to the direct effect of EMF on biological tissue. Slight increase of
LF-HRV and decrease of HF-HRV and RR was observed after $60 \mathrm{~min}$. what correlates with the maximum measured auricular temperature in rabbits. The average temperature reached its maximum during $60 \mathrm{~min}$. of the exposure following by balanced ear temperature values for the remaining periods. There were no statistically significant changes in the temperature pattern in the group 2, only recurring oscillations that cannot be correlated with other characteristics of the HRV analysis. The aim of the thermoregulatory behavior is optimizing a heat transfer from the body to the environment and vice versa (Morrison and Nakamura 2011). Mechanisms for thermal protection also include thermoregulatory procedures of skin vasodilation for increasing heat loss by the activity of the sympathetic nervous system, which is primarily responsible for increasing skin blood flow in the hyperthermic environment (Kinugasa and Hirayanagi 1999). Heating could also cause a tachycardic reaction, mediated mainly by attenuation of the vagal activity. These data suggest that thermoregulatory changes in skin blood flow during hyperthermia are mediated by the sympathetic activity of the premotor neurons located in a rostral raphe complex of a spinal cord (Kataoka et al. 2014, Nakamura et al. 2005). Thus, in addition to non-thermal effect, we can hypothesize also potential thermal effects of RF EMF. However, further research is needed. The $\alpha$-chloralose lowers the temperature by its action on the walls of the ventral half of the third ventricle containing the hypothalamic nuclei (Feldberg and Myers, 1965). Therefore, in the group 2 the infrared lamp was used to keep the normal body temperature range at $38-40{ }^{\circ} \mathrm{C}$. The difference in mean body temperature between the groups could be explained as a result of different methodology used for the groups. However, there were no statistically significant changes in body temperature for group 2 .

The results inconsistency of the animal studies seems to be the concern regarding possible effects of EMF. The different observed effects are probably due to different experimental conditions and exposure parameters (e.g. E-field intensity, frequency, time etc.). Also many studies do not well describe the exposure condition such as source of EMF, intensity, power or background EMF at the place of the exposure which are considered to be important for replicating the studies (IARC 2013). This means that the results may not be directly comparable to the available studies.

Limitations of the study

In this study, only within-groups comparison is 
used due to differences in used methodology regarding the effect of anesthesia on cardiovascular control. Therefore, the between-groups comparison could provide additional important information. Moreover, differences in animal species should be taken into account, therefore, the application of these findings to human medicine is still limited.

Of note, it would be necessary to extend the recovery time after the exposure in future research. The 30 min. was shown as a short time to observe the animals' recovery. The lack of monitoring of arterial blood pressure during the exposure and the SAR parameter, which was not calculated, could also be considered.

\section{Conclusion}

Our study revealed the increased HRV parameters (HF-HRV, rMSSD) associated with lower heart rate indicating increased cardiac vagal control under the exposure to RF EMF in experimental methods. We suggest that our findings can serve as a basis for understanding of the pathomechanisms leading to RF EMF linked altered complex heart rate autonomic control in human medicine. Notably, the higher vagal activity could be associated with increased risk of cardiac arrhythmias leading to sudden death, therefore, this issue seems be very important.

\section{Ethical statement}

All procedures on animals were conducted in accordance with the European Guidelines on Laboratory Animal Care and were approved by the Ethical Board of the Jessenius Faculty of Medicine in Martin, Comenius University in Bratislava under permissions covered by project No. APVV-0189-11 (prof. Jakus).

\section{Conflict of Interest}

There is no conflict of interest.

\section{Acknowledgements}

The authors are thankful to Mr. Jozef Vojtek (ELPRA Technik, Martin, Slovakia) for his excellent technical support. This study was supported by Slovak Research and Development Agency under the contract no. APVV0189-11 (prof. Jakus) and the contract no. APVV-190214, the project "Carcinogenic and toxic metals in working environment" (ITMS: 26220220111) cofinanced by EU sources and the European Regional Development Fund and projects VEGA 1/0173/20, VEGA 1/0166/17 and VEGA 1/0044/18.

\section{References}

ALANKO T, HIETANEN M, NANDELSTADH P: Occupational exposure to RF fields from base station antennas on rooftops. Ann Telecommun 63: 125-132, 2008. https://doi.org/10.1007/s12243-007-0001-6

BARABAS J, RADIL R: Evidence of S. Cerevisiae Proliferation Rate Control via Exogenous Low Frequency Electromagnetic Fields. In: Information Technologies in Biomedicine. Itib 2012, 7339: 2012, pp 295-303. Springer, Berlin, Heidelberg. https://doi.org/10.1007/978-3-642-31196-3_29

BARABAS J, RADIL R, MALIKOVA I: Modification of S. cerevisiae growth dynamics using low frequency electromagnetic fields in the $1-2 \mathrm{kHz}$ range. Biomed Res Int 2015: 1-5, 2015. https://doi.org/10.1155/2015/694713

BELYAEV I: Dependence of non-thermal biological effects of microwaves on physical and biological variables: implications for reproducibility and safety standards. European J Oncol Library 5: 187-218, 2010.

BELYAEV I, DEAN A, EGER H, HUBMANN G, JANDRISOVITS R, KERN M, KUNDI M, MOSHAMMER H, LERCHER P, MULLER K, OBERFELD G, OHNSORGE P, PELZMANN P, SCHEINGRABER C, THILL R: European EMF Guideline 2016 for the prevention, diagnosis and treatment of EMF-related health problems and illnesses. Rev Environ Health 31: 363-397, 2016. https://doi.org/10.1515/reveh-2016-0011

BENARROCH EE: The central autonomic network: functional organization, dysfunction, and perspective. Mayo Clinic proceedings, 68: 988-1001, 1993. https://doi.org/10.1016/S0025-6196(12)62272-1

BUJNAKOVA I, ONDREJKA I, MESTANIK M, VISNOVCOVA Z, MESTANIKOVA A, HRTANEK I, FLESKOVA D, CALKOVSKA A, TONHAJZEROVA I: Autism spectrum disorder is associated with $\begin{array}{lllllll}\text { autonomic underarousal. Physiol Res } 65 & \text { (Suppl. } & \text { 5): } & \text { S673-S682, } & 2016 .\end{array}$ https://doi.org/10.33549/physiolres.933528 
CAMM A, MALIK M, BIGGER J, GÜNTER B, CERUTTI S, CHOEN R: Task force of the european society of cardiology and the north american society of pacing and electrophysiology. Heart rate variability: standards of measurement, physiological interpretation and clinical use. Circulation 93: 1043-1065, 1996.

DURDIK M, KOSIK P, MARKOVA E, SOMSEDIKOVA A, GAJDOSECHOVA B, NIKITINA E, HORVATHOVA E, KOZICS K, DAVIS D, BELYAEV I: Microwaves from mobile phone induce reactive oxygen species but not DNA damage, preleukemic fusion genes and apoptosis in hematopoietic stem/progenitor cells. Sci Rep 9: 16182, 2019. https://doi.org/10.1038/s41598-019-52389-x

FORREST MD: Intracellular calcium dynamics permit a Purkinje neuron model to perform toggle and gain computations upon its inputs. Front Comput Neurosci 8: 2014. https://doi.org/10.3389/fncom.2014.00086

GALUSCAK R, HAZDRA P: Dual-band loop feed with enhanced performance. Radioengineering 17: 33-37, 2008.

GHAZIZADEH V, NAZIROGLU M: Electromagnetic radiation (Wi-Fi) and epilepsy induce calcium entry and apoptosis through activation of TRPV1 channel in hippocampus and dorsal root ganglion of rats. Metab Brain Dis 29: 787-799, 2014. https://doi.org/10.1007/s11011-014-9549-9

GMITROV J: Static magnetic field effect on the arterial baroreflex-mediated control of microcirculation: implications for cardiovascular effects due to environmental magnetic fields. Radiat Environ Biophys 46: 281-290, 2007. https://doi.org/10.1007/s00411-007-0115-2

IARC International Agency for Research on cancer. Monographs on the Evaluation of Carcinogenic Risks to Humans. Non-ionizing Radiation, Part 2: Radiofrequency Electromagnetic Fields Lyon, France: IARC Press, http://monographs.iarc.fr/ENG/Monographs/vol102/mono102.pdf. [Last accessed 18 December 2019] 2013.

ICNIRP: Guidelines for limiting exposure to time-varying electric, magnetic, and electromagnetic fields (up to 300 GHz). International commission on non-Ionizing radiation protection. Health Phys 74: 494-522, 1998.

JEONG JH, KIM JS, LEE BC, MIN YS, KIM DS, RYU JS, SOH KS, SEO KM, SOHN UD: Influence of exposure to electromagnetic field on the cardiovascular system. Auton Autacoid Pharmacol 25: 17-23, 2005. https://doi.org/10.1111/j.1474-8673.2004.00328.x

KATAOKA N, HIOKI H, KANEKO T, NAKAMURA K: Psychological stress activates a dorsomedial hypothalamusmedullary raphe circuit driving brown adipose tissue thermogenesis and hyperthermia. Cell Metab 20: 346-358, 2014. https://doi.org/10.1016/j.cmet.2014.05.018

KHADRAWY YA, AHMED NA, ABOULEZZ HS, N.M. R: Effect of electromagnetic radiation from mobile phone on the levels of cortical amino acid neurotransmitters in adult and young rats. Romanian J Biophys 19: 295-305, 2009.

KIM JH, HUH YH, KIM HR: Trafficking of synaptic vesicles is changed at the hypothalamus by exposure to an 835 $\mathrm{MHz}$ radiofrequency electromagnetic field. Gen Physiol Biophys 38: 379-388, 2019a. https://doi.org/10.4149/gpb_2019020

KIM JH, LEE JK, KIM HG, KIM KB, KIM HR: Possible effects of radiofrequency electromagnetic field exposure on central nerve system. Biomol Ther (Seoul) 27: 265-275, 2019b. https://doi.org/10.4062/biomolther.2018.152

KINUGASA H, HIRAYANAGI K: Effects of skin surface cooling and heating on autonomic nervous activity and baroreflex sensitivity in humans. Exp Physiol 84: 369-377, 1999. https://doi.org/10.1111/j.1469445X.1999.01839.X

KOPANI M, FILOVA B, SEVCIK P, KOSNAC D, MISEK J, POLAK S, KOHAN M, MAJOR J, ZDIMALOVA M, JAKUS J: Iron deposition in rabbit cerebellum after exposure to generated and mobile GSM electromagnetic fields. Bratisl Lek Listy 118: 575-579, 2017. https://doi.org/10.4149/BLL_2017_110

KOPPEL T, VILCANE I, AHONEN M: $50 \mathrm{~Hz}$ magnetic field affects heart rate variability - an experimental study. 2018 EMF-Med 1st World Conference on Biomedical Applications of Electromagnetic Fields (EMF-Med), 10-13 Sept. 2018, Split, Croatia, 2018. https://doi.org/10.23919/EMF-MED.2018.8526072

LAZETIC B, NIKIN B: The effect of electromagnetic field on the heart rate of rabbits. Gen Physiol Biophysics 7: 529-535, 1988.

LOEWENSTEIN Y, MAHON S, CHADDERTON P, KITAMURA K, SOMPOLINSKY H, YAROM Y, HAUSSER M: Bistability of cerebellar Purkinje cells modulated by sensory stimulation. Nat Neurosci 8: 202-211, 2005. https://doi.org/10.1038/nn1393 
MASKEY D, KIM M, ARYAL B, PRADHAN J, CHOI IY, PARK KS, SON T, HONG SY, KIM SB, KIM HG, KIM MJ: Effect of $835 \mathrm{MHz}$ radiofrequency radiation exposure on calcium binding proteins in the hippocampus of the mouse brain. Brain Res 1313: 232-241, 2010. https://doi.org/10.1016/j.brainres.2009.11.079

MISEK J, BELYAEV I, JAKUSOVA V, TONHAJZEROVA I, BARABAS J, JAKUS J: Heart rate variability affected by radiofrequency electromagnetic field in adolescent students. Bioelectromagnetics 39: 277-288, 2018a. https://doi.org/10.1002/bem.22115

MISEK J, VOJTEK J, VETERNIK M, KOHAN M, JAKUSOVA V, SPANIKOVA G, BELYAEV I, JAKUS J: New radiofrequency exposure system with real telecommunication signals. Advances in Electrical and Electronic Engineering 16: 101-107, 2018b. https://doi.org/10.15598/aeee.v16i1.2768

MOHAMED FA, AHMED AA, EL-KAFOURY BMA, LASHEEN NN: Study of the cardiovascular effects of exposure to electromagnetic field. Life Sci J 8: 260-275, 2011.

MOKRÝ J, REMEŇOVÁ T, JAVORKA K: Changes in respiratory rate, blood pressure and heart rate variability in rabbits during orthostasis. Acta Vet Brno 75: 3-12, 2006. https://doi.org/10.2754/avb200675010003

MORRISON SF, NAKAMURA K: Central neural pathways for thermoregulation. Front Biosci 16: 74-104, 2011. https://doi.org/10.2741/3677

NAKAMURA K, MATSUMURA K, KOBAYASHI S, KANEKO T: Sympathetic premotor neurons mediating thermoregulatory functions. Neurosci Res 51: 1-8, 2005. https://doi.org/10.1016/j.neures.2004.09.007

NOOR NA, MOHAMMED HS, AHMED NA, RADWAN NM: Variations in amino acid neurotransmitters in some brain areas of adult and young male albino rats due to exposure to mobile phone radiation. Eur Rev Med Pharmacol Sci 15: 729-742, 2011.

PALL ML: Scientific evidence contradicts findings and assumptions of Canadian Safety Panel 6: microwaves act through voltage-gated calcium channel activation to induce biological impacts at non-thermal levels, supporting a paradigm shift for microwave/lower frequency electromagnetic field action. Rev Environ Health 30: 99-116, 2015. https://doi.org/10.1515/reveh-2015-0001

PARAZZINI M, RAVAZZANI P, THUROCZY G, MOLNAR FB, ARDESI G, SACCHETTINI A, MAINARDI LT: Nonlinear heart rate variability measures under electromagnetic fields produced by GSM cellular phones. Electromagn Biol Med 32: 173-181, 2013. https://doi.org/10.3109/15368378.2013.776424

PRŮCHA J, SKOPALIK J, SOCHA V, HANÁKOVÁ L, KNOPFOVÁ L, HÁNA K: Two types of high inductive electromagnetic stimulation and their different effects on endothelial cells. Physiol Res 68: 611-622, 2019. https://doi.org/10.33549/physiolres.933998

PSENAKOVA Z, SMONDRK M, BARABAS J, LO SCIUTO G, BENOVA M: Simulation and Assessment of Pacemaker RF Exposure (2.4 GHz) by PIFA Antenna. 2016 Elektro 11th International Conference: 569-573, 2016. https://doi.org/10.1109/ELEKTRO.2016.7512141

RAČEK A, BEŇOVÁ K, ARNOUL P, ZÁVODSKÁ M, ANGELIDIS A, CIGÁNKOVÁ V, ŠIMAIOVÁ V, RAČEKOVÁ E: Age-dependent effect of long-term microwave radiation on postnatal neurogenesis in rats: Morphological and behavioral study. Physiol Res 67: 495-503, 2018. https://doi.org/10.33549/physiolres.933752

SAILI L, HANINI A, SMIRANI C, AZZOUZ I, AZZOUZ A, SAKLY M, ABDELMELEK H, BOUSLAMA Z: Effects of acute exposure to WIFI signals $(2.45 \mathrm{GHz})$ on heart variability and blood pressure in Albinos rabbit. Environ Toxicol Pharmacol 40: 600-605, 2015. https://doi.org/10.1016/j.etap.2015.08.015

SHAFFER F, GINSBERG JP: An overview of heart rate variability metrics and norms. Front Public Health 5: 258, 2017. https://doi.org/10.3389/fpubh.2017.00258

SKLEROV M, DAYAN E, BROWNER N: Functional neuroimaging of the central autonomic network: recent developments and clinical implications. Clin Auton Res 29: 555-566, 2019. https://doi.org/10.1007/s10286$\underline{018-0577-0}$

SMONDRK M, BENOVA M, PSENAKOVA Z: Evaluation of SAR in Human Body Model Comprising of Implanted $\begin{array}{llllll}\text { Pacemaker. } & \text { 12th } & \text { International }\end{array}$ https://doi.org/10.1109/ELEKTRO.2018.8398336

THAYER JF, LANE RD: A model of neurovisceral integration in emotion regulation and dysregulation. Journal of affective disorders, 61: 201-216, 2000. https://doi.org/10.1016/S0165-0327(00)00338-4 
TRZASKA H: Engineering Problems in Bioelectromagnetics. In Electromagnetic Fields in Biology and Medicine. M MARKOV (Ed) CRC Press, Boca Raton, London, New York, 2015. pp. 69-78. https://doi.org/10.1201/b18148-7

VANGELOVA K, DEYANOV C, ISRAEL M: Cardiovascular risk in operators under radiofrequency electromagnetic radiation. Int J Hyg Environ Health 209: 133-8, 2006. https://doi.org/10.1016/j.ijheh.2005.09.008

VETERNIK M, TONHAJZEROVA I, MISEK J, JAKUSOVA V, HUDECKOVA H, JAKUS J: The impact of sound exposure on heart rate variability in adolescent students. Physiol Res 67: 695-702, 2018. https://doi.org/10.33549/physiolres.933882

YARTSEV MM, GIVON-MAYO R, MALLER M, DONCHIN O: Pausing Purkinje cells in the cerebellum of the awake cat. Front Systems Neurosci 3, 2009. https://doi.org/10.3389/neuro.06.002.2009

YU C, PENG RY: Biological effects and mechanisms of shortwave radiation: a review. Mil Med Res 4: $24,2017$. https://doi.org/10.1186/s40779-017-0133-6 